\title{
Pistachio Hulls, A New Source of Fruit Waste for Wool Dyeing
}

\section{Amir Kiumarsi ${ }^{1 *}$ and Mazeyar Parvinzadeh Gashti²}

${ }^{1}$ Department of Chemistry and Biology, Ryerson University, Toronto, Canada

${ }^{2}$ Department of Textile, College of Engineering, Yadegar-e-Imam Khomeini (RAH) Branch, Islamic Azad University, Tehran, Iran

\begin{abstract}
Natural dyes have been employed in dyeing Persian carpet piles for many years. In this study, the dried pistachio hulls were powdered and used for dyeing wool yarns. The Iranian wool yarn was first scoured with nonionic detergent and mordanted using some metal salts including $\mathrm{Cu}, \mathrm{Cr}$ and $\mathrm{Al}$. It was then dyed with different amounts of dried pistachio hull powder. Taguchi statistical method was employed to find the effective factors and results of the planned experiments, in order to optimize the dyeing factors. $A L_{18}$ orthogonal array (seven factors in three levels) was employed to evaluate the effects of different parameters in dyeing process. The colorimetric properties of the dyed yarns were evaluated in CIELAB system. Pistachio hulls found to have good agronomic potential as a natural dye in Iran. Metal mordants when used in conjunction with pistachio hulls were found to enhance the dyeability and its fastness properties. The stepwise process of dyeing with pre-mordanting showed to be energy and time saving and found to achieve high dye retention. Therefore this natural dye has good scope in the commercial dyeing of wool yarns used as Persian carpet piles.
\end{abstract}

Keywords: Natural dye; Wool dyeing; Mordant; Pistachio hull; Taguchi

\section{Introduction}

Today, natural colorants are emerging globally due to the fact that are safer and environment-friendly and thus the application of natural dyes should be considered as a better alternative to synthetic dyes. Using natural dyes contributes to the added value of textiles and also responses to the increasing demand of compatibility with the environment [1-7]. From the point of color chemist view, the actual coloring matters used and the methods by which they were so skillfully applied are of considerable interest. So, it is necessary to study and modify the ways of using natural materials in textiles [5,7]. Many studies have been done on natural dyes covering such areas as: variation in the quantity of dyes concerning natural sources, combination of dyes, properties of natural dyes, effects of mordant and auxiliaries on different properties of dyed samples, light fastness behavior of natural dyes, improvement in natural dyes production and discovering other natural dye sources [8-16]. The colorimetric properties of natural yellow dyes including henna (lawsonia inermis), dolu (rheum emodi), kamala (mallotus phillipinensis), onion (allium cepa) and turmeric (curcuma tinctoria) with different mordants have been studied by Gulrajani et al. [11-13]. Tsatsaroni and Eleftheriadis also discussed the color and fastness of natural saffron [17]. Many research papers have been published on natural dyes and mordanting but a few papers have been published on the alteration of all different factors in one approach. Pistacia vera L., from family Anacardiaceae, genus Pistacia is a small tree up to 10 meters tall, with deciduous pinnate leaves and edible delicious nuts. It is native to southwestern Asia and Asia Minor, from Syria to the Caucasus, Iran, Turkey and Afghanistan. There are archaeological evidences of pistachio nuts were used for food as early as 7,000 B.C. The plant was then introduced to Italy from Syria early in the first century A.D. Subsequently, its cultivation spread over other Mediterranean countries, USA, Australia and China. Botanically a drupe consists of Pericarp (ovary wall) (hull), Endocarp (shell) and ripened ovule (seed) that is the edible portion. Pericarp, in turn, consists of Exocarp and Mesocarp. Pistachio hulls are the byproduct of nut production, which is usually useless. Iran is the world's leading pistachio producer and produces over 350 thousands metric tons every year. There are thousands tons of pistachio hull wastes which can be used as a valuable source of natural dye for carpet piles. To optimize the design of an existing process, it is necessary to identify which factors have the greatest influences and which appropriate values produce the most consistent performance. Experimenting with the design variables, one at a time or by trial and error, until a first feasible design found would be a common approach to process optimization. However, this approach could lead one to a very long and expensive time span in completing the design process. A technique for laying out the experiments when multiple factors involved is popularly known as the "factorial design of experiments". This method helps researchers to determine possible combinations of factors and to identify the best combination. Since it is extremely costly to run a number of experiments to test all combinations, application of a full factorial design of experiments is restricted when many factors and levels are studied. The statistical experimental analysis is proposed to investigate the significances of systematic effects. The application of this kind of experiments requires careful planning, prudent layout of experiment, and expert analysis of results. A commonly applied statistical method, Taguchi experimental design and analysis of variance (ANOVA), could be used to analyze results of the experiments on the response and to determine how much variation quality influencing factors contribute [18-25]. Orthogonal arrays can be used to assign factors to a series of experimental combinations, in which results could then be analyzed by using a common mathematical procedure. The variables can generally be grouped into two major classifications: (a) independent variables or factors, and (b) dependent variables or responses. In this factorial design, the main effects of independent variables and the interactions between dependent variables can be studied. The latter would be the

*Corresponding author: Amir Kiumarsi, Department of Chemistry and Biology, Ryerson University, Toronto, Canada, Tel: 509-335-1858; E-mail akiumarsi@ryerson.ca

Received January 02, 2015; Accepted March 10, 2015; Published April 25, 2015

Citation: Kiumarsi A, Gashti MP (2015) Pistachio Hulls, A New Source of Fruit Waste for Wool Dyeing. J Textile Sci Eng 5: 185. doi:10.4172/2165-8064.1000185

Copyright: ( $) 2015$ Kiumarsi A, et al. This is an open-access article distributed under the terms of the Creative Commons Attribution License, which permits unrestricted use, distribution, and reproduction in any medium, provided the original author and source are credited. 
major advantage of this technique while a major disadvantage for oneat-a-time variable testing method.

In this research, the usage of the dried pistachio hulls for dyeing wool yarns was studied. To achieve the maximum color strength of wool samples dyed with the pistachio hulls with a minimum number of experiments, a Taguchi experimental design $\mathrm{L}_{18}$ orthogonal array (seven factors in three levels and one factor in 2 levels) was employed to evaluate the effect of different factors in the dyeing process. The Iranian wool yarn was first scoured with a nonionic detergent and mordanted with some metal salts including: $\mathrm{KAl}\left(\mathrm{SO}_{4}\right)_{2}, \mathrm{CuSO}_{4}$, and $\mathrm{K}_{2} \mathrm{Cr}_{2} \mathrm{O}_{7}$. The yarn was then dyed with different amounts of dried pistachio hull powder. The colorimetric properties of the dyed yarns were evaluated in CIELAB system.

\section{Experimental}

\section{Materials}

The following materials were used:

- Iranian wool yarns of 432/2 Tex with 144 twists per meter.

- Nonionic detergent (Shirley Development Limited) for scouring of wool yarns.

- Aluminum potassium sulfate $\left(\mathrm{KAl}\left(\mathrm{SO}_{4}\right)_{2}\right)$, copper sulfate $\left(\mathrm{CuSO}_{4}\right)$ and potassium dichromate $\left(\mathrm{K}_{2} \mathrm{Cr}_{2} \mathrm{O}_{7}\right)$ from Merck for mordanting process.

- Hydrochloric acid and sodium hydroxide for controlling the $\mathrm{pH}$.

- Dried powdered pistachio hulls from genus Pistacia vera $L$. collected from Kerman province, Iran.

\section{Procedure}

The wool yarns were treated in four steps as follows:

Scouring: Wool yarns were scoured with $0.5 \%$ nonionic detergents for 30 minutes at $50^{\circ} \mathrm{C}$. The $\mathrm{L}: \mathrm{G}$ (Liquor to Good ratio) of the scouring bath was kept at 40:1. The scoured material was thoroughly washed with tap water and dried at room temperature. The scoured material was soaked in clean water for 30 minutes prior to dyeing or mordanting.

Mordanting: The scoured wool yarns were mordanted with $\mathrm{KAl}\left(\mathrm{SO}_{4}\right)_{2}, \mathrm{CuSO}_{4}$, and $\mathrm{K}_{2} \mathrm{Cr}_{2} \mathrm{O}_{7}$. The $\mathrm{L}: \mathrm{G}$ of the mordanting bath was kept at 40:1. Hydrochloric acid was used in the mordanting bath for adjusting the $\mathrm{pH}$ at 5 . The mordanting temperature was started at $40^{\circ} \mathrm{C}$ and then gradually raised to the required temperature during $20 \mathrm{~min}$ and kept at this temperature for $1 \mathrm{hr}$. The mordanted material was then rinsed with water thoroughly, squeezed and dried.

Dyeing: First the dye solution was prepared by pouring the appropriate amount of dye powder in water for 24 hours before dyeing. Then, the dyeing process was carried out. Dyeing started at $40^{\circ} \mathrm{C}$ and temperature was raised to required temperature in 20 minutes and resumed at this temperature $1 \mathrm{hr}$. The $\mathrm{pH}$ of the dyebath was kept at
$\mathrm{pH}=5$ using dilute acid or base. The dyed material was then rinsed with water thoroughly, squeezed and dried.

Measuring of color strength: To investigate the effects of different parameters on the reflectance spectra of dyed samples, a GretagMacbeth spectrophotometer model $7000 \mathrm{~A}$ computer integrated, was used. CIELAB color co-ordinates $\left(\mathrm{L}^{*}, \mathrm{a}^{*}, \mathrm{~b}^{*}, \mathrm{C}\right)$ and color strength values $(\mathrm{K} / \mathrm{S})$ were calculated from the reflectance data $(\mathrm{R})$ of dyed samples for $10^{\circ}$ observer and D65 illuminant based on the Kubelka-Munk equation:

$$
K / S=\frac{(1-R)^{2}}{2 R}
$$

In which, $\mathrm{K}$, is the sorption coefficient, $\mathrm{R}$ is the reflectance of the dyed sample and $\mathrm{S}$ is the scattering coefficient.

\section{Results and Discussion}

In this research work, the optimization of the dyeing factors in applying the pistachio hulls as a new source of natural dye for wool yarns was carried out employing Taguchi method for statistical design of experiments. According to Taguchi parameter design methodology, one experimental design should be selected for the controllable factors. $\mathrm{A} \mathrm{L}_{18}$ orthogonal array (that accommodates seven factors in three levels and one factor in two levels each in 18 runs) was employed to identify the optimum conditions for dyeing wool yarns with pistachio hulls [25]. Seven influencing factors were taken into account and one column was set for the determination of errors as following:

- Amount of colorant (A)

- Amount of mordant (B)

- Type of mordant $(\mathrm{C})$

- Temperature of mordanting bath (D)

- Temperature of dyeing bath (E)

- Duration of mordanting (F)

- Duration of dyeing $(\mathrm{G})$

The three levels of factors were selected in accordance with the preliminary test and the previous author's experience [26,27]. The factors and levels considered for this experiment are shown in Table 1. The K/S ratios for all samples from different conditions was calculated and shown in Table 2. In these experiments, the system was optimized according to the maximum response value of $(\mathrm{K} / \mathrm{S})$. The analysis of the variance (ANOVA) was employed to determine the factors influencing the average response (K/S) ratios. Table 3 presents the degree of freedom (df), the sum of squares (SS), the mean square (variance, $\mathrm{V}$ ), and the $\mathrm{F}$ ratio of variances $(\mathrm{F})$. The insignificant factors are pooled to reduce the chance of making alpha mistakes. As a role, the factor, which influence is $10 \%$ or lower than the most influential factor is pooled [25]. The F-Value implies that the model is significant. One column was set for the determination of errors to consider the effects

\begin{tabular}{|c|c|c|c|c|c|c|c|}
\hline Levels & $\begin{array}{l}\text { Amount of } \\
\text { colorant, A (g) }\end{array}$ & $\begin{array}{l}\text { Amount of } \\
\text { mordant, B (g) }\end{array}$ & $\begin{array}{c}\text { Type of } \\
\text { mordant, } \mathrm{C}\end{array}$ & $\begin{array}{l}\text { Temp. of mordanting } \\
\text { bath, } D\left({ }^{\circ} \mathrm{C}\right)\end{array}$ & $\begin{array}{l}\text { Temp. of dyeing } \\
\text { bath, } E\left({ }^{\circ} \mathrm{C}\right)\end{array}$ & $\begin{array}{c}\text { Duration of } \\
\text { mordanting, } F \text { min }\end{array}$ & $\begin{array}{l}\text { Duration of dyeing, } \\
\text { G min }\end{array}$ \\
\hline 1 & 0.4 & 2 & $\mathrm{Cr}$ & 50 & 60 & 30 & 60 \\
\hline 2 & 0.1 & 5 & $\mathrm{Al}$ & 70 & 80 & 60 & 90 \\
\hline 3 & 2 & 10 & $\mathrm{Cu}$ & Boil & Boil & 120 & 120 \\
\hline Optimum & 0.4 & 2 & $\mathrm{Cu}$ & 50 & 60 & 120 & 120 \\
\hline
\end{tabular}

Table 1: Studied levels of different factors and the optimum level. 


\begin{tabular}{|c|c|c|c|c|c|c|c|c|c|}
\hline Factors & Error & A & B & C & D & E & F & G & K/S \\
\hline Exp. No & & & & & & & & & \\
\hline 1 & 1 & 1 & 1 & 1 & 1 & 1 & 1 & 1 & 0.06077 \\
\hline 2 & 1 & 1 & 2 & 2 & 2 & 2 & 2 & 2 & 0.05804 \\
\hline 3 & 1 & 1 & 3 & 3 & 3 & 3 & 3 & 3 & 0.06073 \\
\hline 4 & 1 & 2 & 1 & 1 & 2 & 2 & 3 & 3 & 0.05729 \\
\hline 5 & 1 & 2 & 2 & 2 & 3 & 3 & 1 & 1 & 0.04999 \\
\hline 6 & 1 & 2 & 3 & 3 & 1 & 1 & 2 & 2 & 0.05730 \\
\hline 7 & 1 & 3 & 1 & 2 & 1 & 3 & 2 & 3 & 0.05911 \\
\hline 8 & 1 & 3 & 2 & 3 & 2 & 1 & 3 & 1 & 0.05747 \\
\hline 9 & 1 & 3 & 3 & 1 & 3 & 2 & 1 & 2 & 0.04033 \\
\hline 10 & 2 & 1 & 1 & 3 & 3 & 2 & 2 & 1 & 0.06026 \\
\hline 11 & 2 & 1 & 2 & 1 & 1 & 3 & 3 & 2 & 0.05847 \\
\hline 12 & 2 & 1 & 3 & 2 & 2 & 1 & 1 & 3 & 0.05652 \\
\hline 13 & 2 & 2 & 1 & 2 & 3 & 1 & 3 & 2 & 0.05753 \\
\hline 14 & 2 & 2 & 2 & 3 & 1 & 2 & 1 & 3 & 0.06043 \\
\hline 15 & 2 & 2 & 3 & 1 & 2 & 3 & 2 & 1 & 0.05233 \\
\hline 16 & 2 & 3 & 1 & 3 & 2 & 3 & 1 & 2 & 0.05796 \\
\hline 17 & 2 & 3 & 2 & 1 & 3 & 1 & 2 & 3 & 0.05720 \\
\hline 18 & 2 & 3 & 3 & 2 & 1 & 2 & 3 & 1 & 0.05714 \\
\hline
\end{tabular}

Table 2: Design of experiments (DOE) and the calculated K/S ratios for different conditions.

\begin{tabular}{|c|c|c|c|c|}
\hline & df & SS & V & F \\
\hline Error & 1 & $1.56968 \mathrm{E}-05$ & $1.56968 \mathrm{E}-05$ & 1.742903 \\
\hline A & 2 & $6.01627 \mathrm{E}-05$ & $3.00813 \mathrm{E}-05$ & 3.340098 \\
\hline B & 2 & $6.90913 \mathrm{E}-05$ & $3.45457 \mathrm{E}-05$ & 3.835796 \\
\hline C & 2 & $6.45276 \mathrm{E}-05$ & $3.22638 \mathrm{E}-05$ & 3.582426 \\
\hline D & 2 & $6.15764 \mathrm{E}-05$ & $3.07882 \mathrm{E}-05$ & 3.418584 \\
\hline E & 2 & $1.49631 \mathrm{E}-05$ & $7.48157 \mathrm{E}-06$ & 0.83072 \\
\hline F & 2 & $4.80049 \mathrm{E}-05$ & $2.40024 \mathrm{E}-05$ & 2.665124 \\
\hline G & 2 & $3.9758 \mathrm{E}-05$ & & \\
\hline e & 2 & $3.2291 \mathrm{E}-05$ & & \\
\hline (e) & 4 & $3.60245 \mathrm{E}-05$ & $9.00613 \mathrm{E}-06$ & \\
\hline Sum & 17 & $4.06072 \mathrm{E}-04$ & & \\
\hline
\end{tabular}

Table 3: The analysis of the variance (ANOVA) for samples dyed with pistachio hulls.

of factors excluded from the experiment and/or Uncontrollable factors (beta mistakes).

The variation of $\mathrm{K} / \mathrm{S}$ against the different levels of factors is shown in Figure 1.

The response of software calculation shows that the optimum levels of each factor are as follows:

- Amount of colorant at level 1 (0.4 g).

- Amount of mordant at level 1 (2.0 g).

- Type of mordant at level $3\left(\mathrm{CuSO}_{4}\right)$.

- Temperature of mordanting bath at level $1\left(50^{\circ} \mathrm{C}\right)$.

- Temperature of dyeing bath at level $1\left(60^{\circ} \mathrm{C}\right)$.

- Duration of mordanting at level 3 (120 min).

- Duration of dyeing at level 3 (120 min).

The ANOVA predicts the maximum value of $\mathrm{K} / \mathrm{S}=0.7$ for the above optimum conditions. It also suggests that the factors influencing the dye absorption of the wool yarn are of different importance and that the most important factor is the amount of mordant $(\mathrm{F}=3.835796)$

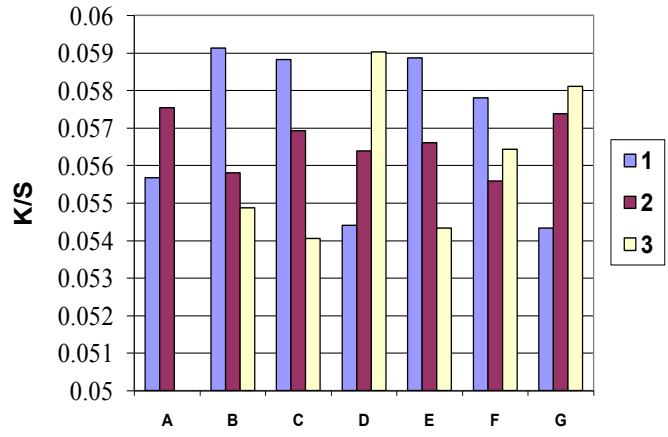

Figure 1: The K/S of different levels of factors.

followed by the type of mordant $(\mathrm{F}=3.582426)$, and temperature of mordanting bath $(\mathrm{F}=3.418584)$. The amount of colorant is the forth most important factor presenting the $\mathrm{F}$ ratio of 3.340098. The higher the percent influence of a factor, the tighter the tolerance, and vice versa.

\section{Effect of mordant}

Most of the natural dyes have poor affinity for natural fibers. Moreover, their fastness is often enhanced by metal mordants, which form an insoluble complex with the dye molecules. It is known that flavonols have greater tendency towards chelate formation due to the presence of hydroxyl-keto functionality $[28,29]$. The probable way of chelation depends on the nature of the mordant-dye complex which has been discussed earlier [27]. Mordant makes strong coordination bonds with the wool yarn on one side and the colorant molecule on the other side. The dye molecules are capable of forming five- and sixmembered chelate rings with different metal ions. These chelates utilize the ortho-dihydroxy structure and/or carbonyl ortho to the hydroxyl group in the flavonol dye molecules, which in turn greatly enhance the affinity of natural dye and fiber. Therefore the type and amount of mordant is of the great importance to make such chelation [27].

\section{Conclusion}

The use of the experimental design is described for optimizing analytical methods. Many factors can be studied, so the interactions can be determined. In addition to the factors identified as being significant, they have more credibility since they are studied several times. The Taguchi's method simplifies both the assignments of factors and the calculations.

The designs described in this work include three level factors. The results and analysis of the variance show that the above-mentioned conditions were considered as optimum. Experiments were carried out at the stated levels, and the optimum conditions were achieved. Confirming experiments were also carried out. Limitations to the experimental design may be seemed obvious, but they are worth being stated, neglecting them often leads to the failing of this approach. The variance observed for a factor is only valid over the range studied for that factor. Pistachio hulls found to have good agronomic potential as a natural dye in Iran. Metal mordants when used in conjunction with pistachio hulls were found to enhance the dyeability and its fastness properties. The color shades on wool yarns ranges from light orange to dark orange. The stepwise process of dyeing with pre-mordanting showed to be energy and time saving and found to achieve high dye 
Citation: Kiumarsi A, Gashti MP (2015) Pistachio Hulls, A New Source of Fruit Waste for Wool Dyeing. J Textile Sci Eng 5: 185. doi:10.4172/21658064.1000185

retention. Therefore this natural dye has good scope in the commercial dyeing of wool yarns used as Persian carpet piles.

\section{Acknowledgement}

The authors express their sincere thanks to Institute for Color Science and Technology of Iran (ICST) for financial support.

\section{References}

1. Kirk Othmer (1998) Encyclopedia of Chemical Technology. John Wiley and Sons, New york, USA.

2. Parvinzadeh Gashti M, Katozian B, Shaver M, Kiumarsi A (2014) Clay nanoadsorbent as an environmentally friendly substitute for mordants in the natural dyeing of carpet piles. Color Technol 130: 54-61.

3. Parvinzadeh M (2007) Effect of proteolytic enzyme on dyeing of wool with madder. Enzym Microb Technol 40: 1719-1722.

4. Anavian R, Anavian G (1975) Royal Persian and Kashmir brocades. Senshoku to Seikatsusha Ltd, Japan 5-24

5. Parvinzadeh M (2009) An Environmentally Method for Dyeing Rug Pile using Fruit Waste Colorant. Res J Chem Environ 13: 49-53.

6. Montazer M, Parvinzadeh M, Kiumarsi A (2004) Colorimetric properties of wool dyed with natural dyes after treatment with ammonia. Color Technol 120 161-166.

7. Montazer M, Parvinzadeh M (2004) Effect of ammonia on madder-dyed natura protein fiber. J Appl Polym Sci 93: 2704-2710.

8. Perkin AG, Everest AG (1918) The natural organic coloring matters. Longman publications.

9. Moir M, Thomson RH (1973) Naphthaquinones in Lomatia species. Phytochem 12: $1351-1353$

10. Takeda N, Seo S, Ogihara Y, Sankawa U, Itaka I, et al. (1973) Studies on fungal metabolites-XXXI: Anthraquinonoid colouring matters of Penicillium islandicum sopp and some other fungi (-)luteoskyrin, (-)rubroskyrin, (+) rugulosin and their related compounds. Tetrahedron 29: 3703-3719.

11. Gulrajani ML, Gupta D, Agrawal V, Jain M (1992) Indian Text J 102: 50.

12. Gulrajani ML, Gupta D, Agrawal V (1992) Indian Text J 102: 85

13. Gulrajani ML, Gupta D, Agrawal V (1992) Indian Text J 102: 76.
14. Montazer M, Parvinzadeh M (2007) Dyeing of wool with Marigold and its properties. Fibers Polym 8: 181-186.

15. Nishiba K, Kobayashi K (1999) Dyeing properties of natural dyes from natural sources. Am Dyestuff Rep 81: 44.

16. Balazsy AT, Eastop D (1998) Chemical principles of textile conservation, John Wiley Ltd.

17. Tsatsaroni EG, Eleftheriadis IC (1994) The colour and fastness of natural Saffron. J. S. D. C. 110: 313

18. Hicks CR (1982) Fundamental concept in the Design of Experiments. Holt, Rinehart and Winston, Inc. New York.

19. Fisher RA, Yates F (1953) Statistical Tables for Biological, Agricultural, and Medical Research. Oliver and Boyd, Edinburgh.

20. Bayne C, Rubin I (1979) In practical Experimental Designs and Optimization Methods for Chemists. VCH Publisher Inc., New York.

21. Duckworth WE (1968) Statistical Techniques in Technological Research: An aid to research productivity. Methuen, London.

22. Taguchi G (1987) System of Experimental Design. Vol.1, KRAUS International publisher

23. Taguchi G (1987) System of Experimental Design. Vol.2, KRAUS International publisher.

24. Montgomery Doglas C (1991) Design and Analysis of Experiments. John Willy and Sons, USA.

25. Roy RK (2001) Design of Experiments Using the Taguchi Approach. Wiley, USA.

26. Parvinzadeh M, Moradian S, Rashidi A, Yazdanshenas ME (2010) Effect of the Addition of Modified Nanoclays on the Surface Properties of the Resultant Polyethylene Terephthalate/Clay Nanocomposites. Polym-Plast Technol 49: 874-884.

27. Parvinzadeh M, Kiumarsi A (2008) Using Eggplant Skin as a Source of Fruit Waste Colorant for Dyeing Wool Fibers. Prog Color, Colorants and Coat 1: $37-43$.

28. Bayer E, Egeter H, Fink A, Nether K, Wegmann K (1966) Complex Formation and Flower Colors. Angew Chem Int Ed 5: 791-798.

29. Ferreira ESB, Hulme AN, McNab H, Quye A (2004) The natural constituents of historical textile dyes. Chem Soc Rev 33: 329-336. 